\title{
Elective surgeries during COVID-19 storm: The best surgeon knows when not to operate
}

\author{
O. Şahap Atik, MD (D) \\ Professor of Orthopedic Surgery, Turkish Joint Diseases Foundation, Ankara, Turkey
}

We are still living with the global threat of coronavirus disease 2019 (COVID-19) storm. We must be optimistic as well as cautious.

What about elective surgeries during COVID-19 storm? Of course, decision remains to be the responsibility of local health officials and those clinicians who have direct responsibility for their patients.

A randomized controlled trial yields important evidence for the treatment of complex proximal humeral fractures in elderly patients suggesting minimal benefits of reverse shoulder arthroplasty over nonoperative treatment for displaced three- and four-part proximal humeral fractures. ${ }^{[1]}$

Whether arthroscopic partial meniscectomy for symptomatic patients with a meniscal tear and knee osteoarthritis results in better functional outcomes than nonoperative therapy is uncertain. In the intention-to-treat analysis, Katz et al. ${ }^{[2]}$ did not find any significant differences between the study groups in functional improvement six months after randomization; and only $30 \%$ of the patients who were assigned to physical therapy alone underwent surgery within six months. We also know that degenerative horizontal tear of the medial meniscus should not be

Received: May 12, 2020

Accepted: June 03, 2020

Published online: June 18, 2020

Correspondence: $O$. Şahap Atik, MD. Turkish Joint Diseases Foundation, Mustafa Kemal Mah., Dumlupınar Bul., 274/2, C2 Blok, Ofis 5, 06900 Çankaya, Ankara, Türkiye.

E-mail: satikmd@gmail.com

Doi: $10.5606 /$ ehc. 2020.57893

Citation: Atik OŞ. Elective surgeries during COVID-19 storm: The best surgeon knows when not to operate. Jt Dis Relat Surg 2020;31(2):161-162. treated with surgery. ${ }^{[3]}$ Another study comparing the results of conservative treatment and arthroscopic treatment of meniscal tear showed that the results of conservative treatment were as satisfactory as that of surgical treatment. ${ }^{[4]}$ It is concluded that our priority as orthopedic surgeons must be to treat the patient, not the imaging results.

Patients with osteoarthritis of the knee who underwent physical therapy had less pain and functional disability at one year than patients who received an intraarticular glucocorticoid injection. ${ }^{[5]}$

Surgical versus conservative treatment for torn anterior cruciate ligament (ACL) is another controversial issue. ${ }^{[6]}$ There are some indications for non-surgical treatment with a strict neuromuscular rehabilitation program. Neuromuscular rehabilitation is also necessary prior to and after ACL reconstruction. This is crucial for primary and secondary preventions as well.

Finally, what about elective surgeries during COVID-19 storm? I believe the right answer is that "the best surgeon knows when not to operate, even if there is no storm".

\section{REFERENCES}

1. Lopiz Y, Alcobía-Díaz B, Galán-Olleros M, GarcíaFernández C, Picado AL, Marco F. Reverse shoulder arthroplasty versus nonoperative treatment for 3- or 4-part proximal humeral fractures in elderly patients: a prospective randomized controlled trial. J Shoulder Elbow Surg 2019;28:2259-71.

2. Katz JN, Brophy RH, Chaisson CE, de Chaves L, Cole BJ, Dahm DL, et al. Surgery versus physical therapy for a meniscal tear and osteoarthritis. N Engl J Med 2013;368:1675-84.

3. Atik OŞ. Should degenerative horizontal tear of the medial meniscus be treated with surgery? Eklem Hastalik Cerrahisi 2018;29:63-4.

4. Karakoç Y, Atalay İB. The role of magnetic resonance 
imaging and clinical assessments in predicting meniscal tear surgery. Eklem Hastalik Cerrahisi 2019;30:85-90.

5. Deyle GD, Allen CS, Allison SC, Gill NW, Hando BR, Petersen EJ, et al. Physical Therapy versus Glucocorticoid
Injection for Osteoarthritis of the Knee. N Engl J Med 2020;382:1420-9.

6. Atik OŞ. Surgical versus conservative treatment for torn anterior cruciate ligament. Jt Dis Relat Surg 2020;31:159-60. 